\title{
THE COVID-19 DISEASE AND POLICY RESPONSE TO MITIGATE THE ECONOMIC IMPACT IN THE EU
}

\author{
Marek ZINECKER (D)1, Karel DOUBRAVSKÝ (D) ${ }^{1}$, Adam P. BALCERZAK (D) 1,2*, \\ Michał Bernard PIETRZAK (iD) ${ }^{3}$, Mirko DOHNAL (D)1 \\ ${ }^{1}$ Faculty of Business and Management, Brno University of Technology, Brno, Czech Republic \\ ${ }^{2}$ Faculty of Economic Sciences, University of Warmia and Mazury in Olsztyn, Olsztyn, Poland \\ ${ }^{3}$ Faculty of Economic Sicences and Management, Nicolaus Copernicus University in Toruń, \\ Toruń, Poland
}

Received 13 October 2020; accepted 07 February 2021

\begin{abstract}
This study aims to understand how Covid-19 contagious disease and the EU's policy response may affect macroeconomic performance. Previous studies on this topic have used historical data sets on "rare macroeconomic disasters" such as Great Influenza to assess the impact of the current pandemic on the global economy. The authors examine the main channels of transmission and targeted policy response to mitigate crisis qualitatively. The authors use heuristics and apply qualitative trend-based analysis because the current pandemic is a unique event for which accurate quantitative data are not currently available. Researchers first identify a set of eight variables based on previous academic theories. They then express each variable as a trend: ascending, descending, and constant. The numerical calculations consist of 17 scenarios, supplemented by 24 transitions and a transition graph. Besides, the article proposes a graphical solution to examine the change in GDP that is too small. The results of the study should be understood as a reference point to allow both private and public stakeholders to understand better the relationship between the observed variables and their dynamics. The research provides a comprehensive list of future events to examine further the implications for the economy as a whole and each individual.
\end{abstract}

Keywords: Covid-19, economic impact, GDP, qualitative trend-based analysis, model, scenarios.

JEL Classification: E17, E52, E58, E31, E62.

\section{Introduction}

Recently, there is an increasing number of studies addressing the issue how the Covid-19 spread across countries might affect the global economy (Kufel, 2020; Dias et al., 2020). Not surprisingly, many authors agree that as a result of the pandemic, we might face the most serious economic and social crisis since the outbreak of the Great Depression in 1929 (Boissay \& Rungcharoenkitkul, 2020; Correia et al., 2020; European Commission, 2020; McKibbin \&

${ }^{*}$ Corresponding author. E-mail: a.balcerzak@uwm.edu.pl

Copyright $\odot 2021$ The Author(s). Published by Vilnius Gediminas Technical University

This is an Open Access article distributed under the terms of the Creative Commons Attribution License (http://creativecommons. org/licenses/by/4.0/), which permits unrestricted use, distribution, and reproduction in any medium, provided the original author and source are credited. 
Fernando, 2020; OECD, 2020; UNCTAD, 2020). The European Commission (2020) indicates four channels through which the Covid-19 pandemic has been affecting the economy. Firstly, China's substantial decline in economic activity in the first quarter of 2020 had worrying effects on the consumer sentiment and resulted in the disruption of global supply chains. Secondly, the introduction of social distancing policies and the global lockdown caused absences from the workplace and deepened the problem of disrupted supply chains. The third channel through which the disease outbreak affects the global economy is a weak demand sentiment caused by rising unemployment, mobility and travel restrictions, etc. Fourth, the pandemics may also depress financial markets, as the demand for risk assets fell, causing a sharp drop in the prices of equity-based instruments. Serious liquidity constraints for banks, enterprises and households become more likely with the lengthening of the period when emergency measures and a drop in productivity will persist. In this context, two other aspects make the world economy strongly vulnerable to the current epidemics: a high level of globalization with accentuated "cross-country spillovers" and high leverage used to cover consumer and investment expenditures in many segments of private economy (Boissay \& Rungcharoenkitkul, 2020).

How do the national governments and the European Commission respond to alleviate the negative effects of the disease on the economy? An extensive number of measures have been introduced within the recent weeks and months. The national budgets, as well as the EU budget, have been mobilised in order to support small and medium-sized enterprises with working capital loans, funds allowing the implementation of part-time work schemes mitigating the risk of unemployment, and with deferred payments of corporate and value added taxes or social security contributions. Furthermore, containment measures to protect public health are complemented by targeted investments into the health care system. Due to the key role of the financial sector (Pardal et al., 2020), banks are provided with guarantees to avoid a sudden and sharp reduction in the availability of credits to the economy (Korzeb \& Niedziółka, 2020). Moreover, the European Central Bank (ECB) has taken complementary actions to facilitate the flow of credit. The first instrument - the new targeted lending facility - is focused on providing liquidity to banks at a negative interest rate $(-0.75 \%)$. Second, the pandemic emergency purchase programme was initiated consisting in buying public and private sector bonds. For more details, see the European Commission (2020), Boissay \& Rungcharoenkitkul (2020), Gopinath (2020) and Lagarde (2020).

Most of the recent papers used quantitative data sets on previous pandemics and estimations are made in terms of the impact of the current situation on the economic activity. In this paper, we will go beyond these approaches; we assume that behavioural patterns can be explained by heuristics and the qualitative trend analysis is used here to develop and explore how Covid-19 contagious disease and the EU's policy response may affect macroeconomic output. This means that we rely on academic theories and expert estimations how each variable involved in the model might develop. The variables under study are described by triplets, i.e., the first and second qualitative time derivatives are used to approximate the trend. The solutions consist of a set of scenarios and a transitional graph covering all possible future behaviours of the observed variables. Furthermore, a graphic solution was derived to study the behaviour of economic growth on the timeline. 
The rest of the current article is organized as follow. In the next section, we discuss the background of the proposed analysis, which concentrates on the most recent research devoted to the problem of the current and projected economic influence of Covid-19 pandemic. In the next methodology section, we discuss qualitative trend analysis as a method, which has a great potential for analysing rare events, which cannot be precisely described by up-to-todate and accurate data, such as Covid-19 pandemic. Then, we provide a precise presentation of our research contribution. Finally, we end up with discussion and conclusions, which stress the specific value added of our approach.

\section{Theoretical background}

A considerable amount of prior research has extensively assessed the impact of epidemics on the economy. Boissay \& Rungcharoenkitkul (2020) provide a summary of the main outputs of the most prominent studies and methodologies. Attention is then payed to the issue to which extent Covid-19 will impact the global GDP growth. The clearest historical analogy to current events is the 1918 Great Influenza (Spanish flu). This epidemic killed about 39 million people, or 2 per cent of the world's population at the time (Barro et al., 2020). A comparable mortality rate today would result in a substantial loss of human life and long-lasting economic downturn. The authors do not believe that there are some specifics in terms of interactions between supply and demand transmission channels, although they require further research in the field. The economic costs of the Covid-19 shock have to be assessed from both short-term and long-term perspective. Based on recent forecasts, Boissay \& Rungcharoenkitkul (2020) predict a very deep recession in 2020. Estimated annual output losses range between 4 and $4.5 \%$ for the world economy and 5 and $9 \%$ for the US economy. Compared to SARS (2003), H5N1 (2003-19) and Ebola (2014-2016), the costs of Covid-19 are "an order of magnitude higher" and exceed even those of the Great Recession between 2008 and 2009. The potential long-term effects of the disease are also scaring and difficult to calculate. A wave of bankruptcies could disrupt supply chains and cause serious damage to the labour market and productivity.

The OECD (2020) used two approaches to assessing the potential impact of global shutdowns on the economy. The first approach is sector-based, focused on estimating how containment measures might affect individual industries and their outputs. Assumptions are made about the magnitude to which the sectors are likely to be affected. The biggest impact on output will occur within service sectors including tourism, travel and retail because of the restrictions on movement and social distancing. A rather moderate direct impact of lockdowns is assumed in capital intensive industries, although some of them are also adversely affected by supply chain disruptions, particularly the manufacturing of transport vehicles. If an economy-wide shutdown is assumed, the calculations suggest that containment measures could reduce the level of output by $15 \%$ or even more in both well-developed and major emerging market economies if the restrictions should last for the whole year. The second approach of assessing the possible impact of economy-wide shutdowns is based on consumer expenditures. Three categories of spending were identified in order to predict the magnitude of expenditure restraint. First of all, spending requiring direct contact, such as clothing, 
footwear and package holidays, is assumed to be strongly reduced or postponed entirely. Expenditures on local travel, public catering and accommodation services represent the second category. The third category of spending concerns essential items, the consumption of which is assumed to be unaffected. The main conclusion that can be drawn from the calculations is that the performance of a typical G7 economy will reduce by around $20 \%$ in the level of GDP on the annual basis.

McKibbin and Fernando (2020) developed and explored seven scenarios to assess the impact of Covid-19 on the global economy by applying the global intertemporal general equilibrium model with heterogeneous agents (G-Cubed Model). This model captures data for six sectors and twenty-four countries and regions. The calculation results show that in the worst case scenario, the GDP loss would reach $8.4 \%$ in the U.S.A., $6.2 \%$ in China, and 8.4\% within the EU. In absolute amounts, the GDP reduction would be over US\$ 9 trillion in 2020. Furthermore, the authors provide estimates for the impact of the global pandemic on consumption, private investment and equity markets. In terms of capital movements, the prediction is that funds will be shifted from equity into bond markets, and that financial capital will outflow from more affected economies such as China and other developing and emerging economies into "safer harbours" such as the USA, Australia and Europe, with the impact on exchange rates and current account adjustments. In the conclusions, McKibbin and Fernando (2020) require the implementation of monetary, fiscal, and health policy responses. In the short-term, cutting interest rates, fiscal spending increase, reducing social interactions, and dissemination of good hygiene practices seem to be highly effective tools. In the long-term, governments are encouraged to conduct large-scale investments into public health systems and medical research in international co-operation.

Barro et al. (2020) aimed at estimating the macroeconomic impact of the Great Influenza Epidemic of 1918-1920. They used the definition of "rare macroeconomic disasters" as large, instantaneous, and permanent drops in real output over one or more adjacent years by 10 per cent or more (see also Barro \& Ursúa, 2008). Examples of such rare events include wars, depressions, financial crises, and epidemics (Nakamura et al., 2010). Based on this definition, Barro et al. (2020) rank as the most adverse macroeconomic shocks for the world since 1870 World War II, the Great Depression, World War I, and the Great Influenza Epidemic. The authors used the cross-country panel regression analysis to assess the impact of the Great Influenza Epidemic and World War I on the economic growth expressed as growth rates of the real GDP per capita and real consumption per capita. The data set lists values for the period between 1901 and 1929 and covers 42 countries. The calculations indicate that the Great Influenza Epidemic reduced real economic output per capita by 6.0 per cent on average. To compare this result with the impact of other rare macroeconomic disasters, the authors also conducted calculations for World War I. In this respect, the findings suggest that the Grande Guerre has lowered the real per capita GDP by 8.4 per cent in a typical country. Further findings of the study suggest considerable short-term slumps in real returns on stocks and short-term government bills. In conclusion, Barro et al. (2020) offer important research implications, while addressing the issue how the current coronavirus pandemic might affect the global economy. The outlined worst-case scenarios are frightening: the Great Influenza flu mortality rate of 2.0 per cent would cause today about 150 million deaths worldwide, which corresponds to the GDP and consumption decline at the level of 6 per cent, and 8 per 
cent respectively. The findings also support the assumption that higher flu death rates will significantly lower real returns on stocks and short-term government bills.

Correia et al. (2020) deal with two sets of questions. Firstly, the authors address the issue how a pandemic will impact the real economic activity and whether the effects of the economic downturn are likely to be of a short-term or long-term nature. Second, how do "non-pharmaceutical interventions" (NPIs) affect the economic severity of the disease? The economic costs and benefits of NPIs policies are studied and compared, while using U.S. data sets on the 1918 Great Influenza mortality, economic activity, bank balance sheets, and containment measures implemented across states and cities. The study delivers evidence that the pandemic caused "a sharp and persistent" economic decline in terms of industrial production (reduction by $18 \%$ per year), the stock of durable goods, and bank assets. Hence, the economic disruption was unambiguously driven by both supply and demand-side channels. The findings also support the notion that timely and offensive NPIs could reduce destructive economic effects of the Great Influenza. Cities and states that applied containment measures faster could not only flatten the shape of their mortality curves but also of economic performance curves. The evidence on industrial production and bank balance sheets suggests that an early implementation of NPIs enabled a smoother economic recovery after the pandemic. Correia et al. (2020) conclude that the lessons from 1918 are important to study the economic impact of Covid-19; however, they stress that a comparison is possible only to a limited extent. The death rate of the 1918 Great Influenza was significantly greater and the disease affected younger people in particular. The level of globalization and the role of modern communication technologies today also differ significantly, making comparisons more complicated.

Eichenbaum et al. (2020) enhanced the SIR model (susceptible, infected, and recovered or removed) developed by Kermack and McKendrick (1927) to explore the interaction between economic decisions and infectional disease. They suggest that an epidemic will impact the aggregate demand, as well as the aggregate supply. The aggregate supply will be cut down because of constraints on the labour market where a remarkable share of the global working force remains outside the workplace. Additionally, unprecedented policy measures force people to remain under lockdown (Kuc-Czarnecka, 2020). Many households respond to the new situation by decreasing consumption, which shifts the aggregate demand curve to the left. The consecutive outcome of the AS and AD shifts results in a deep global economic downturn. Eichenbaum et al. (2020) modify the canonical SIR model by assuming that if the behaviour of people remained unchanged, the risk of spreading infectious diseases among humans would increase. The resulting concept is referred as the SIR-macro model, the simplest variant of which abstracts from the existence of vaccinations, medical treatments, and limited healthcare capacity. Based on this simple SIR-macro model assuming that between 60 and 70 per cent of the US population will be infected, the authors predict that the aggregate consumption will decline by $4.7 \%$ in the first year of the epidemic. Moreover, the simple SIR-macro model is extended by implementing the assumption that the mortality rate is an increasing function of the number of infected population. In this case, an even more significant decline of the AS and AD can be expected as people reduce their consumption and working hours more aggressively. In subsequent calculations, Eichenbaum et al. (2020) discuss the issue how so far a hypothetical possibility of an effective treatment would change 
the research findings. The central message of the research is as follows: finding a compromise between economic interests to mitigate the short-term recession and containment measures to mitigate adverse health consequences plays a critical role. The best simple containment policy clearly worsens the economic situation but significantly reduces mortality.

Table 1 summarizes the methodologies and calculation results of the studies mentioned above.

Table 1. Research on impact of Covid-19 on economic activity (source: elaborated by the authors)

\begin{tabular}{|c|c|c|}
\hline Studies & Methodology & Estimating the Global Economic Costs \\
\hline $\begin{array}{l}\text { Boissay and } \\
\text { Rungcha- } \\
\text { roenkitkul } \\
(2020)\end{array}$ & $\begin{array}{l}\text { A review of empirical studies on the } \\
\text { economic impact of past epidemics } \\
\text { Private sector forecasts on the GDP } \\
\text { growth rates } \\
\text { Using the difference between current } \\
\text { forecasts and pre-Covid-19 outlook }\end{array}$ & $\begin{array}{l}\text { Short-term effects: annual GDP losses between } \\
4 \text { and } 4.5 \% \text { for the world economy and } 5 \text { and } \\
9 \% \text { for the US economy } \\
\text { Long-term effects: bankruptcies, disrupted } \\
\text { supply chains, and the crisis in the labour } \\
\text { market with a negative impact on productivity }\end{array}$ \\
\hline $\begin{array}{l}\text { OECD } \\
(2020)\end{array}$ & $\begin{array}{l}\text { Sector based forecasts focused } \\
\text { on estimating how containment } \\
\text { measures might affect individual } \\
\text { industries and their outputs } \\
\text { Consumption based forecasts } \\
\text { focused on assessing how economy- } \\
\text { wide shutdowns might affect } \\
\text { consumer expenditures }\end{array}$ & $\begin{array}{l}\text { Annual GDP losses on the level of } 15 \% \text { or } \\
\text { even more in both well-developed and major } \\
\text { emerging market economies } \\
\text { The performance of a typical G7 economy will } \\
\text { reduce by around } 20 \% \text { in the level of GDP on } \\
\text { the annual basis }\end{array}$ \\
\hline $\begin{array}{l}\text { McKibbin } \\
\text { and } \\
\text { Fernando } \\
(2020)\end{array}$ & $\begin{array}{l}\text { Developing scenarios on } \\
\text { macroeconomic outcomes } \\
\text { and financial markets while } \\
\text { using a global intertemporal } \\
\text { general equilibrium model with } \\
\text { heterogeneous agents (G-Cubed } \\
\text { Model) }\end{array}$ & $\begin{array}{l}\text { Calculations for seven scenarios } \\
\text { The worst case scenario: GDP decline in the } \\
\text { USA at the level of } 8.4 \% \text { (globally over US } \$ 9 \\
\text { trillion in 2020). } \\
\text { The most lenient scenario: GDP decline in the } \\
\text { U.S.A. at the level of } 0.1 \% \text { (globally by around } \\
\text { US \$ } 2.4 \text { trillion) }\end{array}$ \\
\hline $\begin{array}{l}\text { Barro et al. } \\
(2020)\end{array}$ & $\begin{array}{l}\text { Cross-country panel regression } \\
\text { analysis to assess impact of the Great } \\
\text { Influenza Epidemic and World War } \\
\text { I on economic growth expressed as } \\
\text { the growth rates of real GDP per } \\
\text { capita and real consumption per } \\
\text { capita } \\
\text { The data set lists values for the } \\
\text { period between } 1901 \text { and } 1929 \text { and } \\
\text { covers } 42 \text { countries }\end{array}$ & $\begin{array}{l}\text { Implications for research how Covid-19 might } \\
\text { affect the global economy } \\
\text { Annual GDP and consumption decline at the } \\
\text { level of } 6 \text { per cent and } 8 \text { per cent respectively } \\
\text { Significantly lower real returns on stocks and } \\
\text { short-term government bills }\end{array}$ \\
\hline $\begin{array}{l}\text { Correia } \\
\text { et al. } \\
(2020)\end{array}$ & $\begin{array}{l}\text { Empirical approach building on the } \\
\text { US data on the } 1918 \text { Great Influenza } \\
\text { Estimating the impact of non- } \\
\text { pharmaceutical interventions on } \\
\text { mortality, economic activity, and } \\
\text { bank balance sheets across states and } \\
\text { cities }\end{array}$ & $\begin{array}{l}\text { The lessons from } 1918 \text { are important to study } \\
\text { in terms of the economic impact of Covid- } 19 \\
\text { However, the comparison is tricky because of } \\
\text { differences in mortality rates, public health } \\
\text { service efficiency, the level of globalization, the } \\
\text { structure of economies, and the role of modern } \\
\text { communication technologies. }\end{array}$ \\
\hline $\begin{array}{l}\text { Eichen- } \\
\text { baum et al. } \\
(2020)\end{array}$ & $\begin{array}{l}\text { Extending the SIR model to study } \\
\text { the equilibrium interaction between } \\
\text { political decisions on containment } \\
\text { measures and epidemic dynamics }\end{array}$ & $\begin{array}{l}\text { The simple SIR-macro model: a decline in } \\
\text { consumption by } 4.7 \% \text { in the first year of } \\
\text { epidemic in the USA } \\
\text { Re-calculating of the model results if an } \\
\text { effective treatment were found }\end{array}$ \\
\hline
\end{tabular}




\section{Methodology}

Bringing together the methodological approaches used in recent academic research, we can conclude that these are based on quantitative data sets of previous pandemics. Many assumptions are made in terms of the current pandemic in order to estimate the impact on the global economic growth. Here, we use a qualitative approach to understand the impact of Covid-19 epidemic and targeted policy measures on GDP.

Qualitative trend analysis (QTA) represents a technique how to deal with rare events which cannot be described by numerical data sets because these are not available or are incomplete (Villez, 2015). Many shallow knowledge items are available just as verbal descriptions based on trends: decreasing, constant, or increasing (Yan et al., 2013). For instance, if an effective treatment of Covid-19 were found, then a sharp increase in GDP can be expected. Villez (2015) reports that a QTA consists of a two-step procedure. In the first step, an abstraction of the quantitative data series is outlined. The second on-the-intuition-based step simulates qualitative features. A time series is divided into time windows (these are called episodes) on the basis of the signs of its derivatives. Pairwise trend relations are a graphical representation of the qualitative descriptions. Objective and subjective knowledge must be synthesized to gain the obvious benefits of objective accuracy and semi-subjective ability of common sense. Typical examples of pairwise trend relations are shown in Figure 1.

In our qualitative model, four variables representing the transmission channels through which Covid-19 epidemic is likely to affect GDP growth $(G)$ are used: supply shock $(S)$, China spillover $(C)$, demand shock $(D)$, and liquidity constraints $(L C)$. Furthermore, four variables focused on assessing the impact of policy measures within the EU are considered: liquidity measures $(L M)$, schemes to alleviate the impact on the labour market $(E)$, instruments to support investments $(I)$, and schemes how to maintain supply chains $(T)$.
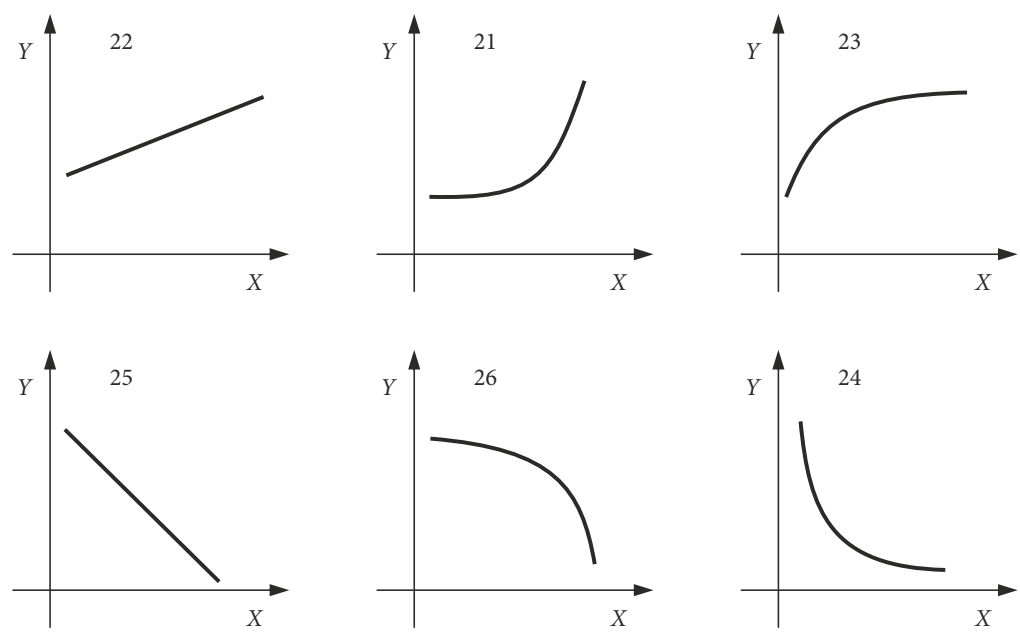

Figure 1. Examples of pairwise trend relations (source: Doubravský \& Dohnal, 2018) 
We build on a still expanding number of studies surrounding the Covid-19 pandemic to shed light on a supply shock, induced by the lockdowns, containment measures, and disrupted supply-side chains, and its effects on aggregate demand (see e.g. Guerrieri et al., 2020; Boissay \& Rungcharoenkitkul, 2020; Eriksson von Allmen et al., 2020). Eriksson von Allmen et al. (2020) suggest that companies in the retail, leisure, tourism, and travel industries have been affected by the crisis first followed by other sectors such as automotive and electronics, which have faced to disrupted supply-side chains. Consequently, the increasing uncertainty, loss of income, rising propensity to save, and a decline in exports have reduced private investment activity and consumption and depress the aggregate demand. The pandemic can also have long-lasting effects on the potential product because of higher mortality, persistent structural unemployment and lower productivity resulting from a wave of bankruptcies. Additionally, Ramsden (2020) emphasizes the "scarring" effect accompanying the post-crisis period, which left firm investment and labour productivity below the pre-crisis levels, due to the initial negative shock. This results in lower household incomes than they might otherwise have been (Ramsden, 2020) and in particular less affluent households are excluded from the use of services provided by, e.g., the financial industry (Huterski et al., 2020).

We distinguish between lottery and decision variables. External supply shocks and China spillovers are lottery variables, i.e., both the national governments and the EU institutions can take either zero or very limited actions to influence them (we call these variables to be off-control). On the other hand, the demand shock and liquidity constraints can be essentially influenced by implementing any kind of measures listed in Figure 2. In this case, we are talking about decision variables, although we recognize that these can be under control only to a certain extent. For instance, short-time work schemes temporarily support employment and companies as they can better match the number of hours worked to output requirements. Without doubt, permanent employment, which can be maintained even during recessions, might be beneficial in the phase of economic recovery and support economic growth. On the other hand, such government-sponsored programmes can also cause market inefficiency (e.g., the reallocation of labour to more productive jobs might be reduced, or freelancers do not benefit from the schemes as they are rather excluded from the labour market, see e.g. Cahuc, 2019). This means that short-time work schemes in terms of promoting economic growth cannot represent a decision variable sensu stricto.

For further details, how transmission channels might influence the GDP growth rates, see Figure 2.

\subsection{Qualitative trend based analysis}

The qualitative trend analysis of the trend model M (see function 1), is based on four quantifiers, see Table 2.

$$
\mathrm{M}\left(X_{1}, X_{2}, \ldots, X_{n}\right) .
$$

Table 2. The quantifiers (source: Vicha \& Dohnal, 2008)

\begin{tabular}{|c|c|c|c|c|}
\hline Values: & Positive & Zero & Negative & Anything \\
\hline Trend: & Increasing & Constant & Decreasing & Any direction \\
\hline Symbol: & + & 0 & - & $\star$ \\
\hline
\end{tabular}



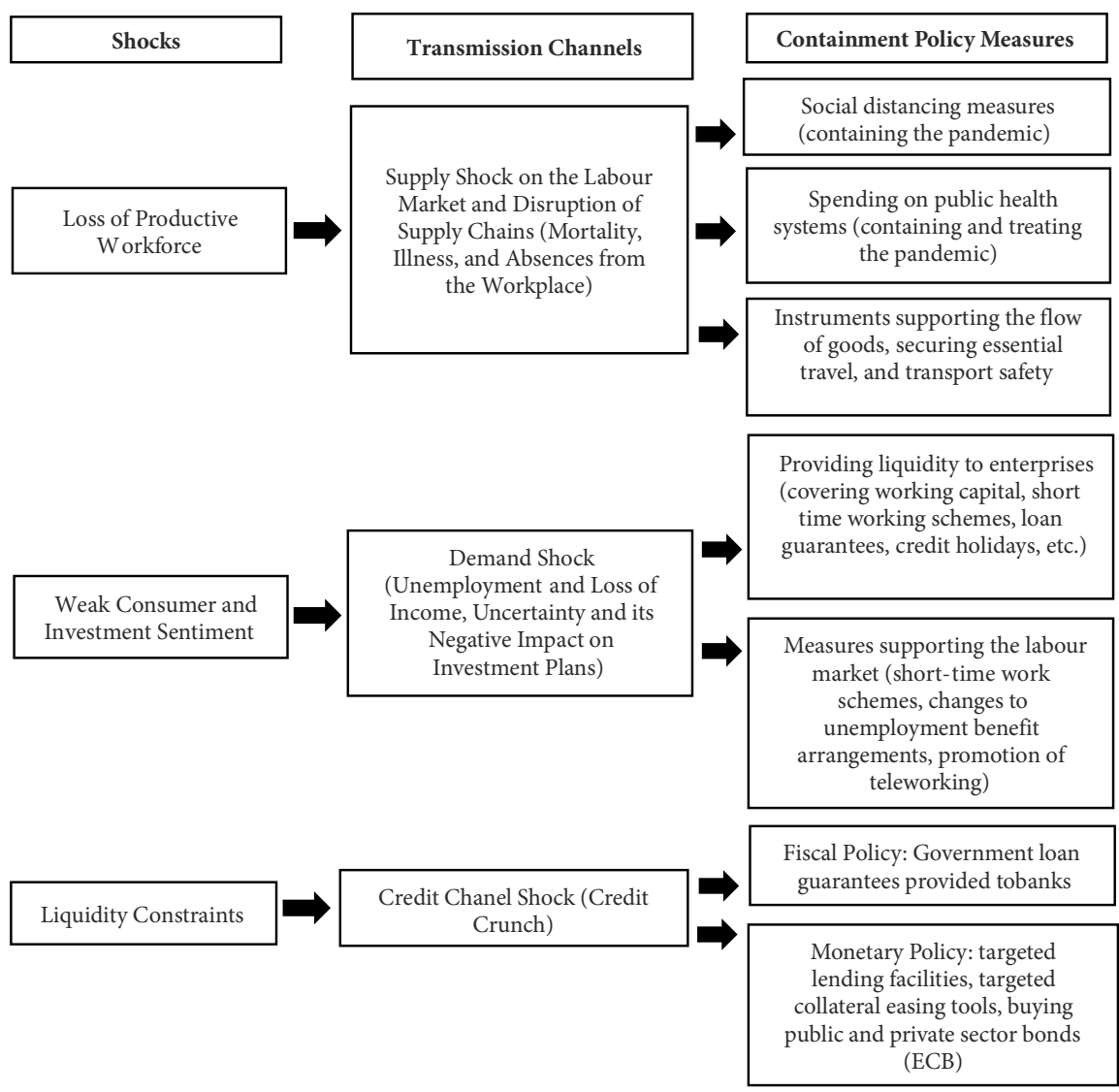

Figure 2. A Schematic Overview of Covid-19 Transmission Channels to the GDP Growth and Containment Policy Measures in the EU

(source: own work based on European Commission, 2020; Boissay \& Rungcharoenkitkul 2020; Gopinath, 2020; Lagarde, 2020)

The trend model $\mathrm{M}$ (function 1 ) is specified when all variables under study $X_{1}, X_{2}, \ldots, X_{n}$ are described by triplets as follows:

$$
\left(X_{i}, \mathrm{D} X_{i}, \mathrm{DD}_{i}\right), i=1,2, \ldots, n,
$$

where $\mathrm{D} X$ is the first qualitative time derivative of $X$ and DDX is the second qualitative time derivative of the variable $X$. For example, the triplet is $(+,+,+)$, shortly $(+++)$. This triplet can be interpreted so that the variable $X$ is positive $(X=(+))$, growing in time $(\mathrm{D} X=(+))$ and growth accelerates $(\mathrm{DDX}=(+))$.

The qualitative trend analysis stands on the elementary conception of derivatives (Doubravský et al., 2020). The trend model $\mathrm{M}$ can be represented by a set of differential equations; for details, see (Vicha \& Dohnal, 2008). When the model (formula 1) is solved, the set of $n$-dimensional scenarios is obtained $\mathrm{S}(n, m)$. There are $m$ scenarios:

$$
\mathrm{S}(n, m)=\left\{\left[\left(X_{1}, \mathrm{D} X_{1}, \mathrm{DD} X_{1}\right),\left(X_{2}, \mathrm{D} X_{2}, \mathrm{DD} X_{2}\right), \ldots,\left(X_{n}, \mathrm{D} X_{n}, \mathrm{DD} X_{\mathrm{n}}\right)\right]_{j}\right\},
$$

where $j=1,2, \ldots, m$. 
Realistic trend models can have hundreds of scenarios, see e.g. Doubravský and Dohnal (2018). A trend shallow model, studied in this paper, is a set of $w$ pairwise relations, see Figure 1.

$$
P_{v}\left(X_{i}, X_{j}\right), v=1,2, \ldots, w .
$$

This set of relations can be solved to evaluate all such scenarios (2) which satisfy the model (1). This paper does not present algorithms which are used to solving trend models, for this purpose see (Vicha \& Dohnal, 2008; Doubravský \& Dohnal, 2018).

For example, the following three-dimensional scenario, $n=3$, indicates that $X_{1}$ is increasing more and more rapidly, $X_{2}$ decreases linearly, $X_{3}$ is decreasing more and more rapidly.

$$
\begin{array}{ccc}
X_{1} ; & X_{2} ; & X_{3} . \\
(+++) & (+-0) & (+--)
\end{array}
$$

It is possible to introduce higher trend derivatives, e.g. the third derivative DDDX. However, knowledge of complex variables is usually so poor that this is rarely possible, see (Bredeweg et al., 2016).

For example, the following trend based model $\mathrm{M}$ is studied:

$\begin{array}{cccc}\text { Shape } & & X & Y \\ 1 & 22(\text { see Figure 1) } & X_{1} & X_{2} \\ 2 & 26(\text { see Figure 1) } & X_{3} & X_{2}\end{array}$

The solution of the model M (4) is represented by 13 three-dimensional scenarios, as shown in Table 3.

If we are not able to decide on a particular trend shape of relations, we use trend relations SUPport and REDuce. The definitions are as follows:

SUP if $X$ is going up (down) then $Y$ is also going up (down);

RED if $X$ is going down (up) then $Y$ is also going up (down).

Table 3. Scenarios (source: Vicha \& Dohnal, 2008)

\begin{tabular}{|c|c|c|c|}
\hline No. & $X_{1}$ & $X_{2}$ & $X_{3}$ \\
\hline 1 & +++ & +++ & +-- \\
\hline 2 & ++0 & ++0 & +-- \\
\hline 3 & ++- & ++- & +-+ \\
\hline 4 & ++- & ++- & +-0 \\
\hline 5 & ++- & ++- & +-- \\
\hline 6 & $+0+$ & $+0+$ & $+0-$ \\
\hline 7 & +00 & +00 & +00 \\
\hline 8 & $+0-$ & $+0-$ & $+0+$ \\
\hline 9 & +-+ & +-+ & ++- \\
\hline 10 & +-0 & +-0 & ++- \\
\hline 11 & +-- & +-- & +++ \\
\hline 12 & +-- & +-- & ++0 \\
\hline 13 & +-- & +-- & ++- \\
\hline
\end{tabular}


It is obvious in Figure 2 that the relations 21, 22, and 23 are the relations with supporting effects, while the relations 24,25 , and 26 are the relations with reducing effects.

\subsection{Transitional graph}

A complete set of all possible one-dimensional transitions is shown in Table 4.

Table 4. The transformation table (source: Dohnal, 1991)

\begin{tabular}{|c|c|c|c|c|c|c|c|c|}
\hline No. & From & To & Or & Or & Or & Or & Or & Or \\
\hline 1 & +++ & ++0 & & & & & & \\
\hline 2 & ++0 & +++ & ++- & & & & & \\
\hline 3 & ++- & ++0 & $+0-$ & +00 & & & & \\
\hline 4 & $+0+$ & +++ & & & & & & \\
\hline 5 & +00 & +++ & +-- & & & & & \\
\hline 6 & $+0-$ & +-- & & & & & & \\
\hline 7 & +-+ & +-0 & $+0+$ & +00 & $0-+$ & $00+$ & 000 & $0-0$ \\
\hline 8 & +-0 & +-+ & +-- & $0-0$ & & & & \\
\hline 9 & +-- & +-0 & $0--$ & $0-0$ & & & & \\
\hline 10 & $0++$ & ++0 & ++- & +++ & & & & \\
\hline 11 & $0+0$ & ++0 & ++- & +++ & & & & \\
\hline 12 & $0+-$ & ++- & & & & & & \\
\hline 13 & $00+$ & +++ & & & & & & \\
\hline 14 & 000 & +++ & --- & & & & & \\
\hline 15 & $00-$ & --- & & & & & & \\
\hline 16 & $0-+$ & --+ & & & & & & \\
\hline 17 & $0-0$ & --0 & --+ & --- & & & & \\
\hline 18 & $0--$ & --0 & --+ & --- & & & & \\
\hline 19 & -++ & -+0 & $0++$ & $0+0$ & & & & \\
\hline 20 & -+0 & -+- & -++ & $0+0$ & & & & \\
\hline 21 & -+- & -+0 & $-0-$ & -00 & $0+-$ & $00-$ & 000 & $0+0$ \\
\hline 22 & $-0+$ & -++ & & & & & & \\
\hline 23 & -00 & -++ & --- & & & & & \\
\hline 24 & $-0-$ & --- & & & & & & \\
\hline 25 & --+ & --0 & $-0+$ & -00 & & & & \\
\hline 26 & --0 & --- & --+ & & & & & \\
\hline 27 & --- & --0 & & & & & & \\
\hline & & & & & \\
\hline
\end{tabular}

Each triplet in the Table 4 can be represented graphically as a pairwise trend relation where one of the observed variables is a time $P\left(\right.$ time, $\left.X_{i}\right)$.

Then transformations listed in the transformation table are based on basic properties of elementary functions of mathematical analysis, such as polynomial functions, rational functions, exponential functions, etc. 
For example, an increasing function cannot change to a decreasing function without crossing a maximum. Therefore, the direct transition between the triplet $(++-)$ to the triplet $(+--)$ is not possible. Or a convex function cannot change to a concave function without crossing an inflection point. Therefore, the direct transition between the triplet $(+++)$ to the triplet $(++-)$ is not possible.

Table 4 is not a dogma and it could be modified on an ad hoc basis.

A transitional graph $\mathrm{H}$ is the directed graph. Its nodes are the set of scenarios $\mathrm{S}$ and $\mathrm{T} \subseteq$ $(\mathrm{S} \times \mathrm{S})$ is the set of the ordered pairs (the transitions).

$$
\mathrm{H}=(\mathrm{S}, \mathrm{T}) \text {. }
$$

The elements of the set $\mathrm{T}$ are the transitions between scenarios $\mathrm{S}$ based on Table 3 . The set of $n$-dimensional transitions $\mathrm{T}$ can be generated by the corresponding set of scenarios $\mathrm{S}$ using Table 3. All $n$ one-dimensional transitions have to be in accordance with Table 3 if $n$-dimensional scenarios are studied. For example, Figure 3 represents the transitional graph $\mathrm{H}$ of scenarios from Table 2 with respecting transitions of Table 3 . Any path is a trend description of a forecast or history. It means that the transitional graph represents all possible future or past behaviors of the model $\mathrm{M}$. Therefore, any forecast is identical to a choice of a path through the transitional graph.

A path is an oriented sequence of scenarios. The graph $\mathrm{H}$ (Eq. (7)) can have loops and therefore a path can pass through the loop infinitely many times. A tree has no loop by definition. Therefore only such a path is studied which is a sub path of a trend tree $\mathrm{R}$ and this tree is a sub-graph of the transitional graph $\mathrm{H}$.

Let the scenario number $i$ be a root scenario of a tree. An analyst must choose the set of terminal scenarios $\mathrm{E}_{i}$ which uniquely specify a trend tree $\mathrm{R}$. This has the scenario $S_{\mathrm{i}}$ as its root and $\mathrm{E}_{i}$ as its set of terminal scenarios:

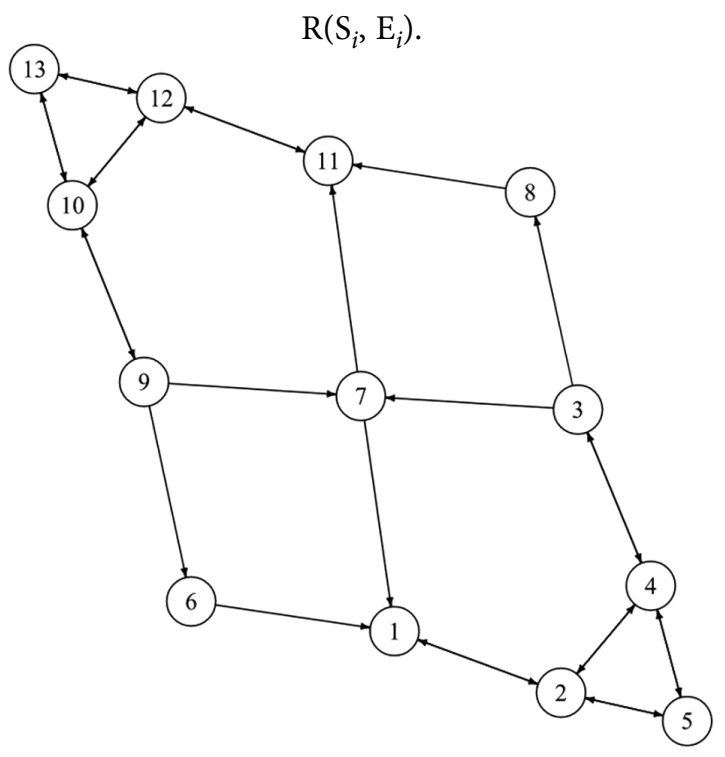

Figure 3. The transitional graph of the trend model M (4) (source: Vicha \& Dohnal, 2008) 


\subsection{Quantifications of trees probabilities}

It is highly desirable to evaluate the probabilities of all or some branches in the tree $\mathrm{R}(8)$. However, the information shortage usually does not allow applying traditional tools. Several different heuristics can be used to formalise common sense reasoning, see (Doubravský \& Dohnal, 2015). Gigerenzer and Gaissmaier (2011) argue that a heuristic is "a strategy that ignores part of the information, with the goal of making decisions more quickly, frugally and/or accurately than more complex methods" (cited in Dosi et al., 2020). When the fundamentals of the economy are uncertain and nonstationary, "heuristics may well be not only reasonable, but also may be rational". When economic agents use heuristics, the accuracy of their forecasts and their well-being may be higher, even higher compared to scenarios where "seemingly more sophisticated rules" were followed (see Dosi et al., 2020). In this paper, for example, the heuristic $\mathrm{H} 1$ is used: we assume that the Covid-19 pandemic triggers an unexpected increase in both costs and disruption in production. This will cause a short-run adverse supply-side shock, leading to substantial changes in aggregate demand. Firm failures and job destruction will, furthermore, aggravate recession and lead public authorities to focus on the potential benefits of monetary and fiscal stimuli to mitigate a severe economic downturn.

The more variables under control are changed to move between the two scenarios, this transition is the most probable. The following algorithm is used to evaluate the numerical probabilities of the tree (8) using the above-mentioned heuristic:

$\mathrm{E}$ - set of terminals,

$\mathrm{N}$ - set of all tree nodes (scenarios),

$l_{i, j}$ - number of changed variables in the transition of $i$-th scenario into $j$-th scenario,

$L_{i}$ - number of changed variables of the sub-tree where $i$ is the sub-root, i.e. variable resistance of $i$-th node.

$$
L_{i}=\sum_{j} l_{i, j},
$$

where $j$ represents nearest node (scenario) of the sub-tree next to the $i$-th node (scenario).

Probability of the transition from $i$-th node (scenario) to $j$-th node (scenario):

$$
p_{i, j}=l_{i, j} / L_{i} \text {, for all } j \in \mathbf{N}-\mathbf{E} \text {. }
$$

Example: The heuristic $\mathrm{H}$ can be used to evaluate the probability (10) of the transition from node 1 to node 3 and the transition from node 1 to node 2, see Figure 4.

$$
\begin{aligned}
& l_{1,2}=4 \\
& l_{1,3}=1+2+3=6 ; \\
& L_{1}=l_{1,2}+l_{1,3}=4+6=10 \\
& p_{1,2}=\frac{l_{1,2}}{L_{1}}=\frac{4}{10}=0.4 ; \\
& p_{1,3}=\frac{l_{1,3}}{L_{1}}=\frac{6}{10}=0.6 .
\end{aligned}
$$




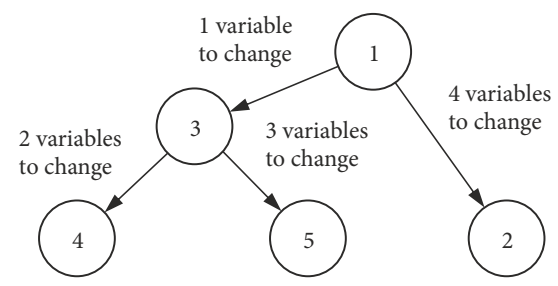

Figure 4. A decision tree (source: elaborated by the authors)

\section{Research results}

This study emerges as a response to the Corona economic crisis characterized by "substantive and procedural uncertainty" (Dosi et al. 2020). The lack of statistical data sets poses a great challenge to researchers and decision makers from both the public and private sectors. Hence, we believe that it is better to accept some general heuristics based on economic theories than big data sets and more sophisticated statistical tools while examining how the Covid-19 contagious disease and policy response may affect macroeconomic performance. The qualitative on-the-trend-based research concept has been applied here to study events and systems, which are unique, vague and multidimensional and thus cannot be described by current adequate data sets (Villez, 2015). The model takes into account a certain number of input variables and results in a set of scenarios and transitions between them.

Four variables representing the transmission channels through which Covid-19 epidemic is likely to affect GDP growth $(G)$ are used: supply shock $(S)$, China spillover $(C)$, demand shock $(D)$, and liquidity constraints $(L C)$. Furthermore, four variables focused on assessing the impact of policy measures within the EU are considered: liquidity measures $(L M)$, schemes to alleviate the impact on the labour market $(E)$, instruments to support investments $(I)$, and schemes how to maintain supply chains $(T)$. For details, see section 2.

The equationless model shown in Table 5 is defined and tested.

Table 5. Equationless model under study (source: elaborated by the authors)

\begin{tabular}{|c|c|c|c|}
\hline No. & Shape, see Figure 1 & X & Y \\
\hline 1 & 21 & S & G \\
\hline 2 & M_- & C & G \\
\hline 3 & 21 & D & G \\
\hline 4 & 21 & LC & G \\
\hline 5 & M_+ & C & S \\
\hline 6 & 23 & S & D \\
\hline 7 & 24 & LC & D \\
\hline 8 & 23 & LC & S \\
\hline 9 & 23 & LM & LC \\
\hline 10 & 21 & LC & G \\
\hline 11 & 23 & E & D \\
\hline 12 & 22 & I & S \\
\hline 13 & 23 & I & E \\
\hline 14 & 22 & T & S \\
\hline
\end{tabular}


The solution represents the set $S$ comprising 17 scenarios, see Table 6 .

A total of 24 possible transitions between all 17 scenarios are generated if the transformation table is used (Table 4). Figure 4 shows a qualitative description of future developments in the form of a transitional graph $G$. Hence, we assume that any path in the graph $G$ illustrates a future behaviour. The forecast documents the possible development of GDP growth rates, which represent the goal variable $\mathrm{V}_{\mathrm{G}}=\{G\}$. It is of crucial importance that the variable $G$ can be controlled by governments. In general, the demand shock can be alleviated by fiscal and monetary policy instruments more effectively than imported supply shocks or spillovers. For example, implementing short-time work schemes or providing liquidity to enterprises might prevent unwanted bankruptcy waves, at least in the short run. Thus, we consider the fiscal and monetary policy instruments to be the decision variables $\mathrm{V}_{\mathrm{D}}=\{E, D, L C, I, L M, T\}$. On the other hand, China spillovers and disrupted supply chains from outside the EU represent variables that might be hardly influenced by policy makers; we talk about off-control variables $\mathrm{V}_{\mathrm{O}}=\{S, C\}$.

The initial node is denoted as 5 and the terminal node is denoted as 15, see Figure 5. Each edge of the transitional graph shows the transition from one node to another one. This transition requires a specific amount of time expressed in certain time units. The oriented paths are of a qualitative nature and show the future behaviour of the variables under study. This means that any forecast in terms of the GDP growth rate is identical to a path through the transitional graph. Therefore, governments and other public and private market participants might be supported in their decision making while using the transition graph.

Table 6. Research results - set of scenarios (source: elaborated by the authors)

\begin{tabular}{|c|c|c|c|c|c|c|c|c|c|}
\hline No. & $\mathrm{S}$ & $\mathrm{G}$ & $\mathrm{C}$ & $\mathrm{E}$ & $\mathrm{D}$ & $\mathrm{LC}$ & $\mathrm{I}$ & $\mathrm{LM}$ & $\mathrm{T}$ \\
\hline 1 & +++ & +++ & +++ & +++ & +++ & +++ & +++ & +++ & +++ \\
\hline 2 & ++- & +++ & +++ & ++- & ++- & +++ & ++- & +++ & ++- \\
\hline 3 & ++- & +++ & ++0 & ++- & ++- & +++ & ++- & +++ & ++- \\
\hline 4 & ++- & +++ & ++- & ++- & ++- & +++ & ++- & +++ & ++- \\
\hline 5 & ++- & ++- & ++- & ++- & ++- & ++- & ++- & +++ & ++- \\
\hline 6 & ++- & ++- & ++- & ++- & ++- & ++- & ++- & ++0 & ++- \\
\hline 7 & ++- & ++- & ++- & ++- & ++- & ++- & ++- & ++- & ++- \\
\hline 8 & $+0+$ & $+0+$ & $+0+$ & $+0+$ & $+0+$ & $+0+$ & $+0+$ & $+0+$ & $+0+$ \\
\hline 9 & +00 & +00 & +00 & +00 & +00 & +00 & +00 & +00 & +00 \\
\hline 10 & $+0-$ & $+0-$ & $+0-$ & $+0-$ & $+0-$ & $+0-$ & $+0-$ & $+0-$ & $+0-$ \\
\hline 11 & +-+ & +-+ & +-+ & +-+ & +-+ & +-+ & +-+ & +-+ & +-+ \\
\hline 12 & +-- & +-+ & +-+ & +-- & +-- & +-+ & +-- & +-+ & +-- \\
\hline 13 & +-- & +-+ & +-0 & +-- & +-- & +-+ & +-- & +-+ & +-- \\
\hline 14 & +-- & +-+ & +-- & +-- & +-- & +-+ & +-- & +-+ & +-- \\
\hline 15 & +-- & +-- & +-- & +-- & +-- & +-- & +-- & +-+ & +-- \\
\hline 16 & +-- & +-- & +-- & +-- & +-- & +-- & +-- & +-0 & +-- \\
\hline 17 & +-- & +-- & +-- & +-- & +-- & +-- & +-- & +-- & +-- \\
\hline
\end{tabular}



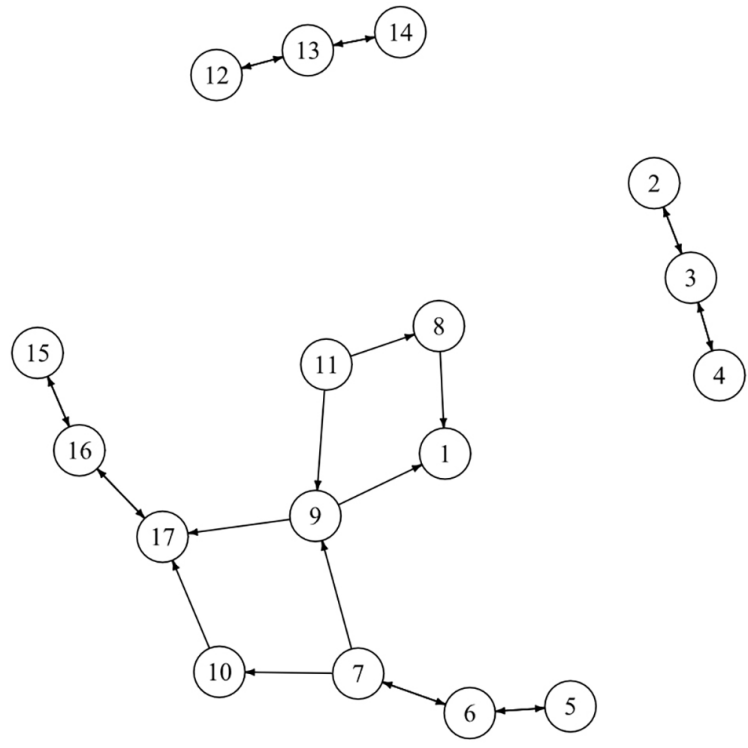

Figure 5. Transitional graph $G$ (source: elaborated by the authors)

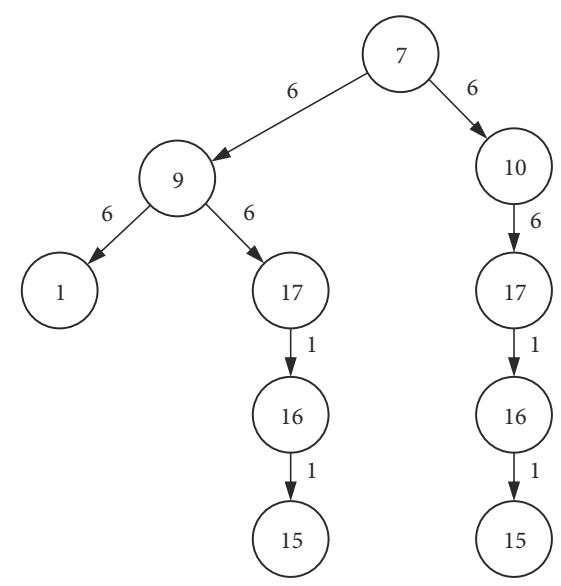

Figure 6. Trend tree (source: elaborated by the authors)

Furthermore, we used the following trend tree (Figure 6) to analyse all available paths, $R\left(S_{7}, \mathbf{E}\right)$, where $\mathbf{E}=\left\{S_{1}, S_{15}\right\}$. Only three paths could be identified, for their description, see Table 7.

Table 7. A comprehensive list of paths (source: elaborated by the authors)

\begin{tabular}{|c|c|}
\hline No. & Path \\
\hline 1 & $7 \rightarrow 9 \rightarrow 1$ \\
\hline 2 & $7 \rightarrow 9 \rightarrow 17 \rightarrow 16 \rightarrow 15$ \\
\hline 3 & $7 \rightarrow 10 \rightarrow 17 \rightarrow 16 \rightarrow 15$ \\
\hline
\end{tabular}


The transition between two nodes (scenarios) is associated with a change of observed variables. In this paper, we focus on the decision variables $\mathrm{V}_{\mathrm{D}}$. For example, the transition from scenario 7 to scenario 9 requires the change of all 6 decision variables (see Table 6 and Figure 5). The number of changed variables is needed to apply the sub-heuristics H1. Numbers of changed decision variables for all transitions $T_{i j}$ shown in Figure 5 are listed in Table 8.

Table 8. Changes of variables (source: elaborated by the authors)

\begin{tabular}{|c|c|c|}
\hline \multicolumn{2}{|c|}{ Transition } & \multirow{2}{*}{ Number of changed variables } \\
\hline From node $i$ & To node $j$ & 6 \\
\hline 7 & 9 & 6 \\
\hline 7 & 10 & 6 \\
\hline 9 & 1 & 6 \\
\hline 9 & 17 & 6 \\
\hline 10 & 17 & 1 \\
\hline 17 & 16 & 1 \\
\hline 16 & 15 & \\
\hline
\end{tabular}

Table 9. Transition probabilities (source: elaborated by the authors)

\begin{tabular}{|c|c|c|}
\hline \multicolumn{2}{|c|}{ Transition } & \multirow{2}{*}{ Probability } \\
\cline { 1 - 2 } From node $i$ & To node $j$ & 0.588 \\
\hline 7 & 9 & 0.412 \\
\hline 7 & 10 & 0.429 \\
\hline 9 & 1 & 0.571 \\
\hline 9 & 17 & 1 \\
\hline 10 & 17 & 1 \\
\hline 17 & 16 & 1 \\
\hline 16 & 15 & \\
\hline
\end{tabular}

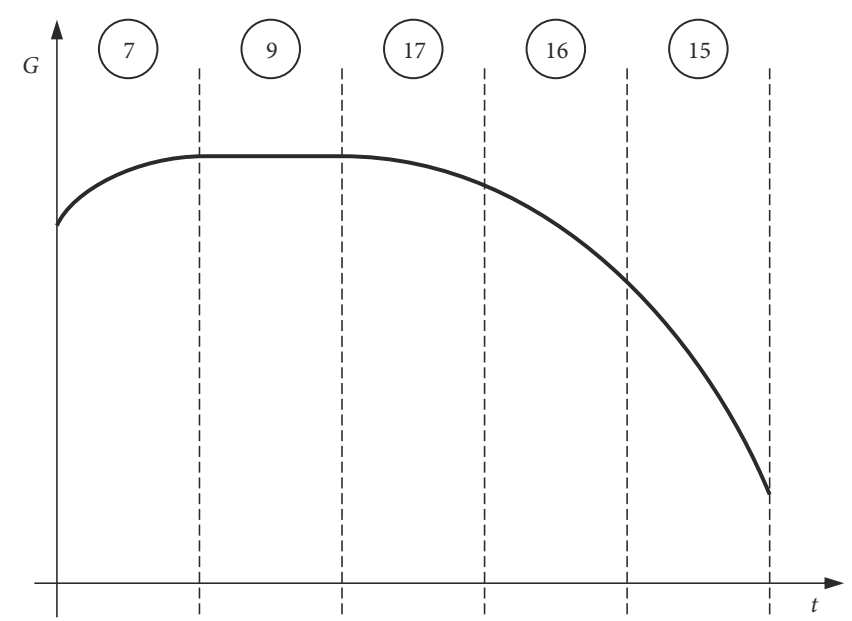

Figure 7. Qualitative description of function $G(\mathrm{t})$ (source: elaborated by the authors) 
On the basis of number of changed variables, see Table 7, the probabilities of the transitions (10) were obtained (see Table 9).

In Table 9, we can see that the most probable path is No. 2, see Table 7. For this path, we can derive the forecast for individual variables over time. For example, the development of the qualitative function $G(\mathrm{t})$ is shown in Figure 7. This graph does not represent a conventional graph. It is a trend graph, which contains five columns, where each column stands for one scenario.

\section{Discussion and conclusions}

In this paper, we aimed at studying how the Covid-19 infectious disease and how the EU policy response might impact macroeconomic outcomes using the qualitative trend analysis. Prior research on the topic has largely worked with historical quantitative data concerning rare events such as the Great Influenza to assess the impacts of the current pandemic on the global economic growth. Unlike these studies, we seek to examine the crucial transmission channels and targeted policy response to mitigate the crisis on a qualitative basis. The qualitative on-the-trend-based research concept has been applied here to study events and systems, which are unique, vague and multidimensional and thus cannot be described by current adequate data sets.

The set S comprising 17 scenarios and the transitional graph G represent the main research outcomes. Moreover, we propose a graphical solution to examine the change of the variables under study over time. The set of scenarios, the transitional graph and the visualization of the development of the GDP growth over time serve as a tool allowing both private and public stakeholders to better understand the relationship between the observed variables and their dynamics. The results of qualitative modelling deliver a complete list of all upcoming events, whose consequences for the economy as a whole and/or each individual can be further studied.

In comparison to other methodological approaches used to study the phenomena, the research approach implemented in this case does not require numerical data sets and sophisticated mathematical tools. This means that the behaviour of the economic system can be studied in many variations; no relevant forecast can be neglected and other additional variables can be integrated into the model. This feature also allows the researchers to carry out any union or intersection of various models. Moreover, all possible time transitions among the gathered scenarios can be determined. Finally, another advantage of the qualitative approach consists in its common sense nature, which makes it very attractive from the perspective of practitioners. Policy makers, corporate managers, investors, analysts, and other stakeholders are provided here with a flexible tool to support effective decision-making.

Certainly, we see a significant potential for more large-scale and more rigorous follow-up research. For example, there is a growing consensus that the possible consequences of the current crisis are of a new and unprecedented scale. Unconventional measures to overcome the crisis have been introduced both on the national and international level. Albeit challenging, an urgent need might occur to implement a wider range of monetary and fiscal instruments within the following weeks and months; thus, more variables and relevant pair-wise relations might be required to be implemented within our model in order to increase the accuracy of the research results. 


\section{Funding}

This work was supported by the Institute of Economic Research Toruń, Poland, and Brno University of Technology, Faculty of Business and Management, Czech Republic (grant number 2019/1). The title of the project is "Public and Private Equity in CEE countries".

\section{Author contributions}

Marek Zinecker conceived the study and was responsible for the design of the study and the interpretation of the research results. Karel Doubravský was responsible for the design and development of the data analysis. Adam Balcerzak and Michal Pietrzak were responsible for the data analysis and interpretation.

\section{Disclosure statement}

All the authors declare that they do not have any competing financial, professional, or personal interests from other parties.

\section{References}

Barro, R. J., \& Ursúa, J. F. (2008). Macroeconomic crises since 1870. Brookings Papers on Economic Activity, 2008, 255-335. https://doi.org/10.1353/eca.0.0000

Barro, R. J., Ursúa, J., F., \& Weng, J. (2020). The coronavirus and the great influenza pandemic: Lessons from the "Spanish Flu" for the coronavirus's potential effects on mortality and economic activity. (Working paper). National Bureau of Economic Research. https://doi.org/10.3386/w26866

Boissay, F., \& Rungcharoenkitkul, P. (2020). Macroeconomic effects of Covid-19: an early review. Bank for International Settlements, Basel. https://www.bis.org/publ/bisbull07.htm

Bredeweg, B., Liem, J., \& Nicolaou, C. (2016). Assessing learner-constructed conceptual models and simulations of dynamic systems. In K. Verbert, M. Sharples, \& T. Klobučar (Eds.), Lecture notes in computer science: Vol. 9891. Adaptive and adaptable learning (pp. 357-362). Springer Verlag. https://doi.org/10.1007/978-3-319-45153-4_27

Cahuc, P. (2019). Short-time work compensation schemes and employment. IZA World of Labor, 11(2), 1. https://doi.org/10.15185/izawol.11.v2

Correia, S., Luck, S., \& Verner, E. (2020). Pandemics depress the economy, public health interventions do not: Evidence from the $1918 \mathrm{flu}$. SSRN. https://doi.org/10.2139/ssrn.3561560

Dias, R., Teixeira, N., Machova, V., Pardal, P., Horak, J., \& Vochozka, M. (2020). Random walks and market efficiency tests: evidence on US, Chinese and European capital markets within the context of the global Covid-19 pandemic. Oeconomia Copernicana, 11(4), 585-608. https://doi.org/10.24136/oc.2020.024

Dohnal, M. (1991). A methodology for common-sense model development. Computers in Industry, 16(2), 141-158. https://doi.org/10.1016/0166-3615(91)90086-O

Dosi, G., Napoletano, M., Roventini, A., Stiglitz, J. E., \& Treibich, T. (2020). Rational heuristics? Expectations and behaviors in evolving economies with heterogeneous interacting agents. Economic Inquiry, 58(3), 1487-1516. https://doi.org/10.1111/ecin.12897 
Doubravský, K., \& Dohnal, M. (2015). Reconciliation of decision-making heuristics based on decision trees topologies and incomplete fuzzy probabilities sets. Plos One, 7(10), 1-18. https://doi.org/10.1371/journal.pone.0131590

Doubravský, K., \& Dohnal, M. (2018). Qualitative equationless macroeconomic models as generators of all possible forecasts based on three trend values - Increasing, constant, decreasing. Structural Change and Economic Dynamics, 45, 30-36. https://doi.org/10.1016/j.strueco.2018.01.001

Doubravský, K., Doskocil, R., \& Dohnal, M. (2020). A dynamic knowledge model of project time-cost analysis based on trend modelling. Periodica Povlytechnica Social and Management Sciences, 28(1), 18-28. https://doi.org/10.3311/PPso.13318

Eichenbaum, M. S., Rebelo, S., \& Trabandt, M. (2020). The macroeconomics of epidemics. (NBER Working Paper Series). https://doi.org/10.3386/w26882

Eriksson von Allmen, U., Jeasakul, P., Kang, H., \& Khera, P. (2020). Macrofinancial considerations for assessing the impact of the COVID-19 pandemic. International Monetary Fund.

European Commission. (2020). Coordinated economic response to the COVID-19 Outbreak. COM(2020) 112 final. Brussels. https://ec.europa.eu/commission/presscorner/detail/en/ip_20_459

Gigerenzer, G., \& Gaissmaier, G. (2011). Heuristic decision making. Annual Review of Psychology, 62, 451-482. https://doi.org/10.1146/annurev-psych-120709-145346

Gopinath, G. (2020, April 14). The Great Lockdown: Worst economic downturn since the Great Depression. IMFBlog. International Monetary Fund, New York. https://blogs.imf.org/2020/04/14/thegreat-lockdown-worst-economic-downturn-since-the-great-depression/

Guerrieri, V., Lorenzoni, G., Straub, L., \& Werning, I. (2020). Macroeconomic implications of Covid-19: Can negative supply shocks cause demand shortages? (NBER Working Paper Series). https://doi.org/10.3386/w26918

Huterski, R., Huterska, A. A., Łapińska, J., \& Zdunek-Rosa, E. (2020). The problem of savings exclusion and gross savings in the new European Union member states. Entrepreneurship and Sustainability Issues, 7(3), 2470-2480. https://doi.org/10.9770/jesi.2020.7.3(67)

Kermack, W. O., \& McKendrick, A. G. (1927). A contribution to the mathematical theory of epidemics. Proceedings of the Royal Society of London, series A 115(772), 700-721. https://doi.org/10.1098/rspa.1927.0118

Korzeb, Z., \& Niedziółka, P. (2020). Resistance of commercial banks to the crisis caused by the COVID-19 pandemic: the case of Poland. Equilibrium. Quarterly Journal of Economics and Economic Policy, 15(2), 205-234. https://doi.org/10.24136/eq.2020.010

Kufel, T. (2020). ARIMA-based forecasting of the dynamics of confirmed Covid-19 cases for selected European countries. Equilibrium. Quarterly Journal of Economics and Economic Policy, 15(2), 181204. https://doi.org/10.24136/eq.2020.009

Kuc-Czarnecka, M. (2020). COVID-19 and digital deprivation in Poland. Oeconomia Copernicana, 11(3), 415-431. https://doi.org/10.24136/oc.2020.017

Lagarde, C. (2020, April 9). How the ECB is helping firms and households. The ECB Blog. https://www. ecb.europa.eu/press/blog/date/2020/html/ecb.blog200409 3aa2815720.en.html

McKibbin, W. J., \& Fernando, R. (2020). The global macroeconomic impacts of COVID-19: Seven scenarios. SSRN. https://doi.org/10.2139/ssrn.3547729

Nakamura, E., Steinsson, J., Barro, R., \& Ursúa, J. (2010). Crises and recoveries in an empirical model of consumption disasters (NBER Working Paper Series, 15920). https://doi.org/10.3386/w15920

OECD. (2020). Evaluating the initial impact of COVID-19 containment measures on economic activity. https://read.oecd-ilibrary.org/view/?ref=126_126496-evgsi2gmqj\&title=Evaluating_the_initial_impact_of_COVID-19_containment_measures_on_economic_activity. 
Pardal, P., Dias, R., Šuleř, P., Teixeira, N., \& Krulický, T. (2020). Integration in Central European capital markets in the context of the global COVID-19 pandemic. Equilibrium. Quarterly Journal of Economics and Economic Policy, 15(4), 627-650. https://doi.org/10.24136/eq.2020.027

Ramsden, D. (2020). The potential long-term economic effects of Covid. Institute for Policy and Engagement, University of Nottingham. http://www.bankofengland.co.uk/news/speeches

UNCTAD. (2020). Global trade impact of the Corona Virus (Covid-19) epidemic. https://unctad.org/en/ PublicationsLibrary/ditcinf2020d1.pdf

Vicha, T., \& Dohnal, M. (2008). Qualitative identification of chaotic systems behaviours. Chaos, Solutions and Fractals, 38(1), 70-78. https://doi.org/10.1016/j.chaos.2008.01.027

Villez, K. (2015). Qualitative path estimation: A fast and reliable algorithm for qualitative trend analysis. AIChE Journal, 61(5), 1535-1546. https://doi.org/10.1002/aic.14736

Yan, X., Zhou, Y., Wen, Y., \& Chai, X. (2013). Qualitative and quantitative integrated modeling for stochastic simulation and optimization. Journal of Applied Mathematics, 2013, 831273.

https://doi.org/10.1155/2013/831273 